\title{
A Game Theoretic Approach to Organic Foods: An Analysis of Asymmetric Information and Policy
}

\author{
Jill J. McCluskey
}

\begin{abstract}
Demand for healthy, safe, and environmentally friendly food products has been increasing. In response, producers are marketing organic and other quality-differentiated foods, sometimes claiming to have followed sound environmental and animal welfare practices. These products frequently have unobservable quality attributes. If the profit-maximizing producer is able to deceive the consumer with a false claim, then he or she will enjoy a higher price with lower production costs (compared to the full disclosure outcome). The analysis described in this paper shows that repeat-purchase relationships and third-party monitoring are required for high-quality credence goods to be available. Policy implications of this analysis for national organic food standards are discussed.
\end{abstract}

In recent years, the increasing number of health conscious, informed, and more demanding consumers has led to an increase in demand for healthy, safe, and environmentally friendly food products. The food industry has responded to this increased demand by offering a wider range of quality-differentiated products (Frazão and Allshouse 1996), including organic foods, products with other nutritional and food safety characteristics, products with claims that they were produced with sound environmental and animal welfare practices, and kosher foods. Food processors and retailers have been quick to use quality claims in marketing these products. The major characteristics that define food product quality attributes include food safety, nutritional, value, packaging and processing (Hooker and Caswell 1996). These food product quality classes are offered with different degrees of asymmetric information.

Asymmetric information problems occur because food producers know whether they have used the appropriate methods to achieve the desired quality attributes, but consumers only know with certainty what the producers' quality claims are or what the label says. The federal government

Jill J. McCluskey is an assistant professor with the Department of $\mathrm{Ag}$ ricultural Economics at Washington State University.

The author wishes to thank, without implicating, Leo Simon, Paul Barkley, and two anonymous reviewers for providing useful comments. regulates food labels, but many quality claims go unmonitored. Therefore, many quality-differentiated food products present problems of imperfect information, which may result in inefficient market outcomes.

There are three classifications of goods based on the consumer's ability to determine quality. These are (1) search goods, (2) experience goods, and (3) credence goods (Nelson 1970; Darby and Karni 1973). Caswell and Mojduszka (1996) applied these classifications to food products in their analysis of informational labeling of food product quality attributes. In the case of search goods, there is perfect information about quality before purchase. Parsley is an example of a search good because it is valued as a garnish based on its fresh appearance. With experience goods, quality can only be determined after the product has been consumed. An example of an experience good is canned food. Quality in a credence good cannot be directly observed (or it is observed too slowly or too late to matter or it is prohibitively costly to be observed) by consumers even after consumption. Examples of credence goods are organic foods, dolphin-safe tuna, free-range meat, and kosher foods.

Organic foods have recently been in the news because of the debate over the establishment of national organic food standards. The 1990 Organic Food Production Act (OFPA) mandated that the 
United States Department of Agriculture (USDA) establish national standards for producing and marketing organic agricultural products and a system of mandatory certification and federal oversight to ensure truth in labeling or organic products (Vandeman and Hayden 1997). Sales of organic foods have experienced rapid growth in recent years. Gross returns increased from \$631 million in 1989 to $\$ 3$ billion in 1996 (Landay 1996). Consumers pay average premiums of $25-30 \%$ for organic produce (Morgan, Barber and Greene 1990), and growers receive up to $250 \%$ more for organic products depending on crop and season (Knoblauch, Brown, and Braster 1990).

The term organic has been applied to both measurable product standards, such as no observed pesticides, ${ }^{1}$ as well as process standards. Under the latter definition, organic foods are distinguished from conventional foods by production and processing principles rather than attributes that are noticeable in the product itself. This philosophy stresses production and processing without the use of synthetic chemicals and soil fertility management that use techniques that enhance biological activity in the soil such as composting, green manuring, and rotating crops (Vandeman and Hayden 1997). Since there is no consensus definition of the term organic, one contribution of a national standard would be to clarify what the term represents.

Given the price premiums for organic foods, the increasing number of health conscious consumers, and the credence-good nature of organic foods, one would expect for there to be some false labeling present in the organic foods market. There have been recent criminal prosecutions of producers who falsely labeled their products as organic. For example, in May of 1998, Petrou Foods, Inc., a San Diego processor of olives, olive oil, and vinegar, pleaded no contest to charges of theft for falsely representing and branding products as organic (Groves 1998). In 1996, the president of Glacial Ridge Foods Company confessed to investigators that his Minnesota-based wholesale firm had been mislabeling ordinary beans and barley as organically grown (Landay 1996).

This analysis has policy implications for organic food issues. First, are national standards desirable? With or without national standards, is third-party monitoring necessary for truth in labeling of organic products? If third-party monitoring is necessary and given that it is costly, what level of monitoring is necessary to ensure truth in labeling?

\footnotetext{
'However, from the consumers' perspective, it would be prohibitively costly for any one consumer to test for the presence of pesticides.
}

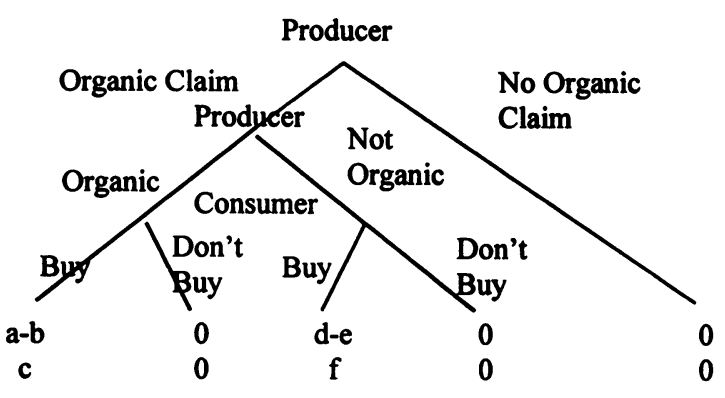

Figure 1. Search Good

Should the government be responsible for monitoring? What other factors contribute to the integrity of organic food products? In order to address these and other policy questions, simple games are analyzed to highlight some of the information issues that are present in markets for qualitydifferentiated food products with asymmetric information, such as organic foods. These games are not intended to reflect accurately the intricacies of the markets for organic foods. Rather, they are intended to shed light on the incentives resulting from the asymmetric information. Although organic foods can usually be classified as credence goods, games are analyzed for all three classifications of goods (search goods, experience goods, and credence goods) for the purpose of analyzing the effects of different types of asymmetric information. The analysis shows that repeat-purchase relationships and third-party monitoring are required for high-quality credence goods to be available. The policy implications of this analysis for national organic food standards are also discussed.

\section{Search Goods}

With perfect information, there is no quality issue. Organic foods would be just like any other product. In equilibrium, consumers will buy organic foods if the marginal utility per dollar they derive from them is at least equal to that of their other purchases. Producers will enter the market until there are no more opportunities to exploit economic profits.

An extensive-form game for a search good is shown in figure 1. In figure 1, the last two rows of the game tree are the payoffs to the players. The upper payoff is to the producer; the lower payoff is to the consumer. The producer's payoff is in dollar units and can be thought of as price less cost. The consumer's payoff is in terms of utility. I assume generally that it is more expensive to produce us- 
ing organic methods. This notation and these conventions will be followed throughout the analysis.

The equilibrium concepts that will be used in this analysis are Nash equilibrium and subgame perfect Nash equilibrium. A Nash equilibrium exists if each player is employing his or her optimal strategy given all the other players' strategies. In other words, each player chooses to play his or her best response to what everyone else is doing. A subgame perfect Nash equilibrium exists when the players' strategy choices result in a Nash equilibrium in every subgame. A consequence of this equilibrium refinement is that all threats must be credible.

In this game, producers decide whether or not to make an organic claim. If a producer chooses to offer products with an organic claim, then he or she must decide whether to use organic methods. If the producer chooses to offer products with an organic claim, then the consumer will buy if he or she is better off doing so, or if $c \geq 0 .^{2}$ Similarly, the consumer will buy the non-organic good if $f \geq 0$. Therefore, it will be a Nash equilibrium for the producer to use organic methods if they are more profitable; that is, if $a-b \geq d-e$ and $a-b \geq 0$.

\section{Experience Goods}

With an experience good, the consumer can ascertain the quality of the product only after consumption. If the buyer and seller only interact one time, then it is as if they are playing a single stage game. Like a prisoners' dilemma game, neither buyer nor seller has an incentive to cooperate. In one-shot relationships, as in Akerlof's (1970) "lemons" result, moral hazard and adverse selection will result in food produced with the lowest-cost methods. A producer who sells experience goods to one-time customers has strong incentives to only sell goods that are at the lowest possible quality level acceptable to the one-time consumer. Therefore, there is moral hazard on the producer side. This problem can be overcome if the producer offers an adequate, enforceable warranty. Grossman (1981) shows that in a one-shot relationship, if sellers are required to be truthful in any disclosures they make about product quality, they will fully disclose the true level of product quality. In the same paper, Grossman shows that if buyers are risk averse, sellers will offer warranties to fully insure against the

\footnotetext{
2 The consumer payoffs may be net of an existence value. That is, even those consumers that do not buy may have a gross payoff that is greater than zero due to the opportunity to purchase organic products in the future. Clearly, this does not alter the model's results.
}

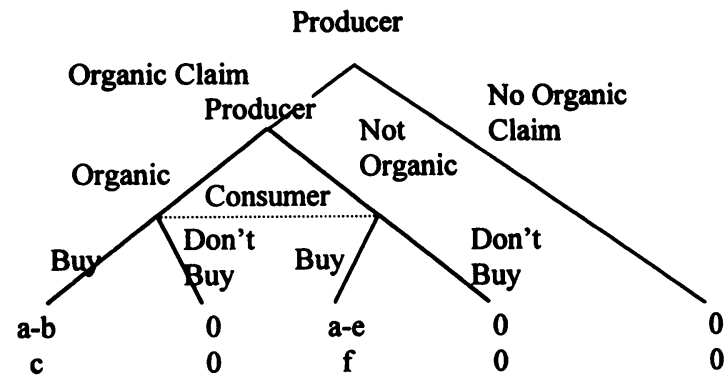

Figure 2. Experience Good

low quality outcome. An extensive-form game for an experience good is shown in figure 2 .

The dotted line between the two decision nodes at the consumer's level is an information set which indicates that the consumer does not know at which node he or she is located. The consumer does not know whether the producer used organic methods. Both the organic and conventional foods have the same quality claim, and the price charged is the same across quality. ${ }^{3}$ The consumer will determine the probability that he or she is at either node and, based on that probability, decide whether to buy the good. In the continuation game, after the producer chooses to make an organic claim, the equilibrium depends on the sign of the consumer's payoff given he or she buys a non-organic product. If $f<0$, the only Nash Equilibrium of the continuation game is the strategy profile (Not Organic, Don't Buy). If $f \geq 0$, then the strategy profile (Not Organic, Buy) is the Nash Equilibrium. There is no Nash Equilibrium in the stage game in which the producer uses organic methods.

If customers have longer-term relationships with sellers, as in a repeat purchase situation, then the problem can be modeled as a repeated game. There is an unraveling effect in the finitely repeated game. With a finite horizon of $T$ periods, the producer has an incentive to cut quality in the last period, and therefore in the next to last, and so on. The market "unravels" to become the one-shot game, repeated $T$ times.

In the finitely repeated game, with a small proportion of producers who are not profit maximizers (crazy types), establishing a reputation can result in cooperation, as shown in Kreps and Wilson (1982) and Milgrom and Roberts (1982). Barro (1986) applied this theory of reputation to monetary policy. In Barro's model the central banker wants to convince everyone that he or she is a "low-

\footnotetext{
${ }^{3}$ The producer who claims he/she is using organic methods but is actually not using those methods must charge the organic price or else reveal that he is not using organic methods.
} 


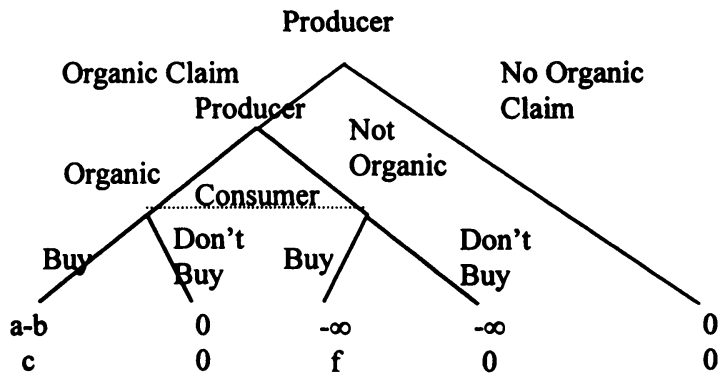

Figure 3. Game that the Organic-Type Producer is Playing

inflation" type. Applying the Kreps-WilsonMilgrom-Roberts theory of reputation to organic foods is straightforward. There is a small probability that the producer is an organic producer type, who will only produce organically grown foods. The organic producer type's payoffs are depicted in figure 3 .

Otherwise, the producer is a profit maximizing type, who will only use organic methods if it maximizes profits to do so. (The profit-maximizing type producer's payoffs are depicted in figure 2.) Even if the profit-maximizing producer's one-shot game choice is to minimize costs, he or she may still produce food with organic methods for a limited number of periods. By following that strategy, the producer keeps open the possibility that he or she might be an organic-producer type; and because of the uncertainty over type, consumers are willing to make repeat purchases. If the horizon is bounded, the profit-maximizing type milks his/her reputation at some point by not using organic methods, which causes consumers to stop purchasing after observing that the food is non-organic. Using a reputation model, the existence of a small percentage of organic producer types makes it possible for profitmaximizing producers to credibly produce organic products.

There is no unraveling effect in the infinitely repeated game. The "folk theorems" for repeated games assert that if the players are sufficiently patient, then any feasible, individually rational payoffs can be enforced by an equilibrium (Fudenberg and Tirole 1993). An application of the folk theorems is that if players are patient enough, then producers can sell experience-good-type organic foods. This can be illustrated with the following proposed strategies, for $f \leq 0$ :

Producer: Use organic methods in the first period. Then produce organic if consumer bought in all preceding periods. Otherwise, do not make organic claim.

Consumer: Buy in the first period. Then buy if
Table 1. Experience Good Payoffs

\begin{tabular}{lcc}
\hline & $\begin{array}{c}\text { Equilibrium } \\
\text { Payoffs }\end{array}$ & $\begin{array}{c}\text { Deviation } \\
\text { Payoffs }\end{array}$ \\
\hline Producer & $\frac{a-b}{1-\delta}$ & $a-e$ \\
Consumer & $\frac{c}{1-\delta}$ & 0 \\
\hline
\end{tabular}

producer used organic methods in all preceding periods. Otherwise, do not buy.

Without loss of generality, assume that both the consumer and producer have identical discount rates equal to $\delta$. The present-value payoffs are listed in table 1 . The deviation payoffs are calculated based on one-stage deviation. ${ }^{4}$

For the producer to use organic methods, it must be that

$$
\frac{a-b}{1-\delta}>a-e
$$

The present value of the stream of payoffs from offering genuine organic foods must be greater than the one-time gain from fooling the consumer with a false organic claim. If the producer is patient, then he or she will have a higher value for the stream of future profits, and the organic equilibrium is possible.

In this model the effective penalty for noncompliance is that consumers will no longer buy the product. Sergerson (1999) analyzes the effect of additional penalties for non-compliance to determine the conditions under which firms are likely to invest in food safety. In addition to a negative consumer demand response, additional possible penalties for non-compliance include the imposition of mandatory controls on the firm, direct government financial inducements such as the loss of subsidies or the imposition of fines, compensation to consumers for damages, and criminal prosecution for fraud.

\section{Credence Goods}

The literature on credence goods has focused on services. Consumers are often unable to judge the quality of the services they receive from doctors, lawyers, and auto mechanics. For example, when a patient recovers from an illness for which he or she

\footnotetext{
${ }^{4}$ See the proof in Rabin (1995) that a strategy profile is a subgame perfect Nash equilibrium if and only if it is one stage deviation proof, $p$. 62, or for a verbal argument, see Tirole (1992), p. 265.
} 
sought medical advice, the patient often does not know whether his/her recovery would have arrived any more quickly without the use of medical services. Ex post, the buyer is uncertain about the quality of goods or services that he or she has purchased. This asymmetric information creates an incentive for fraud in the market for credence goods. For example, in a recent study, the employees of Sears Automotive Centers recommended unnecessary repairs to car owners in $90 \%$ of the test cases (Patterson 1992). The classic article in the literature on credence good is Darby and Karni (1973). They consider how reputation, market conditions, and technological factors affect the amount of fraud. Emons (1997) verifies the existence of equilibria resulting in non-fraudulent behavior when consumers can infer the sellers' incentives from observing market data. Using a model with credence goods, Hamilton, Sunding, and Zilberman (1999) analyze the incentive for fraud using a framework of product diversification in which the conviction probability is endogenous to firms.

With a credence good and no monitoring, there is no premium for an organic claim. Since the consumer does not know the quality of his/her purchase even after consumption, it is not possible for the consumer to punish the producer by not purchasing the product in the future in response to a false quality claim. A long-term relationship in the purchasing of a credence good becomes a series of repeated stage game outcomes with no market for high-quality credence goods.

Since, in practice, consumers do sometimes pay a premium for credence goods, there is monitoring. It may also be that some consumers pay premiums for credence goods for reasons other than quality. It could be that the credence good is fashionable or the alternative to the credence good may offend other people. An example is a consumer who purchases dolphin-safe tuna in order to avoid offending a friend, although the consumer may not believe the tuna is actually dolphin safe. The consumer may want to appear to other people as a person who is making every effort to do the right thing. This type of psychological game is not modeled in this paper. An extensive-form game for a credence good is shown in figure 4 . The consumer receives a utility payoff of $c$ whether the producer used organic methods or not. Therefore, the consumer will buy the product with the organic claim if $c \geq 0$. The producer will then choose the lowest cost method, which is not organic. It does not matter if the game is repeated because the consumer cannot punish the producer for actions he or she cannot observe.

With a credence good, one must assume that the

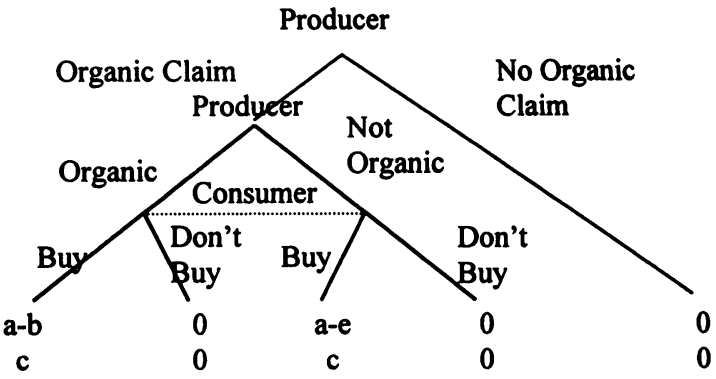

Figure 4. Credence Good

producer's strategy is not common knowledge. This violates a standard assumption in noncooperative game theory that all players' strategies are common knowledge. However, with credence goods, the point is that after consumption, the consumer does not know what the producer did. This is in contrast to experience goods, which can be modeled with the standard game theoretic assumptions. The problem caused by the unobservable nature of a credence good is similar to a Green and Porter (1984) type problem. In Green and Porter's problem, members of a cartel only observe the price of their product. They cannot tell whether price drops are caused by another member cheating or by a demand shock. Similarly, with credencegood-type organic foods, consumers only observe their own payoffs, and they can not determine whether those payoffs were caused by the producer using organic methods.

Is there a role for signaling in marketing organic foods? Spence's (1973) analysis showed that efficient workers can signal their type by education expenditures. Analogously, an organic grower could use an instrument (such as spots or discoloration on fruit) to signal his/her type if the cost from using this instrument is lower than that of a grower who is not using organic methods. Another example of a possible signal is a producer's statement that consumers can visit the production facility to inspect the organic production practices. Are organic labels good signals? If the producer issues the organic label himself with no outside monitoring, then it is just cheap talk in the sense of Farrell (1993). However, if the organic label stands for credible third-party monitoring, then the label is like a guarantee. Caswell and Padberg (1992) discuss the possibility of food labels as the answer to imperfect information dilemma in food safety. Caswell and Mojduszka (1996) argue that quality signaling through product labeling promotes market incentives with relatively limited government involvement. They point out that the monitoring and enforcement activities of the government are 


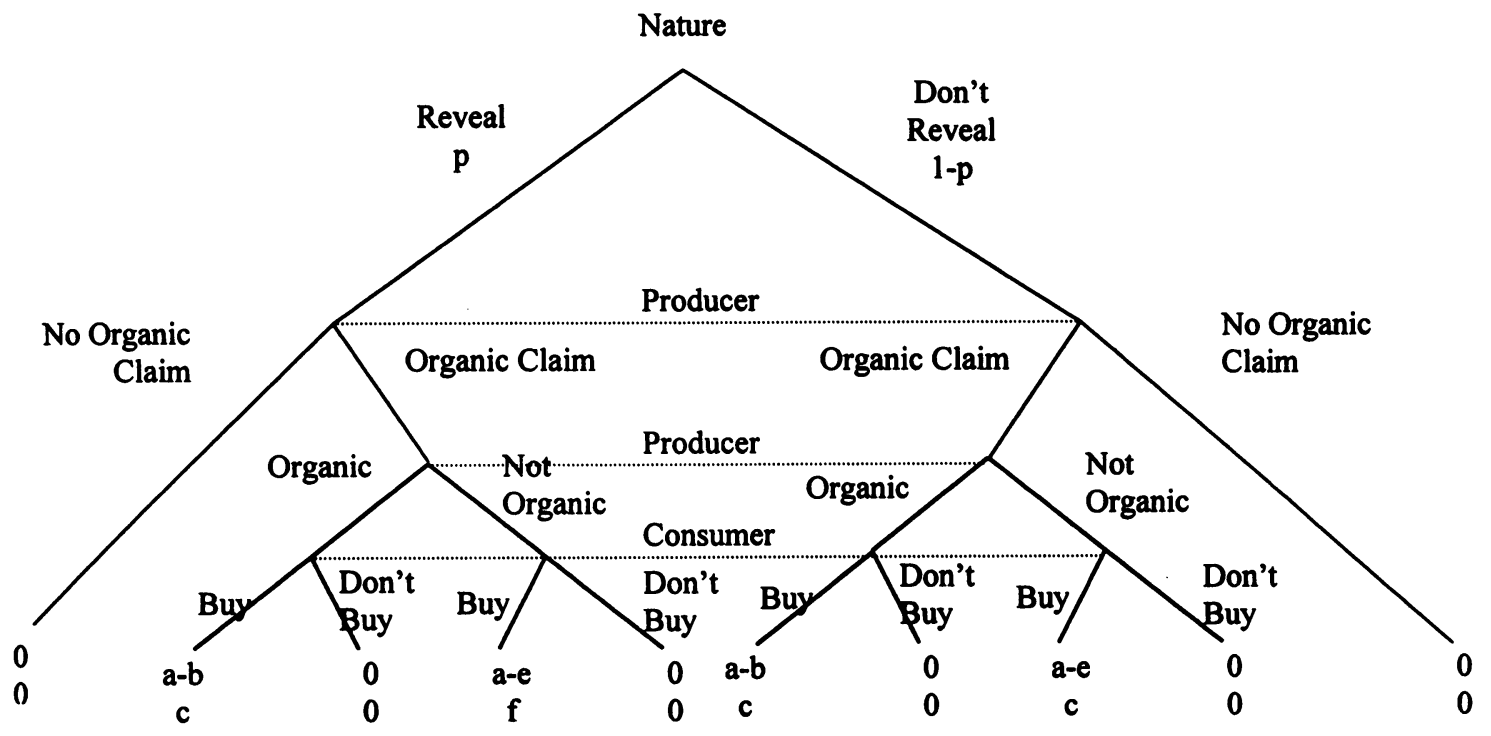

Figure 5. Credence Good with Monitoring

an attempt to ensure that the disclosures made are truthful and credible.

With monitoring, there is a possible market for organic foods. Although certain food quality attributes are credence goods, it is possible for scientists (possibly employed by the government or environmental groups) to monitor the claims of a percentage of all products. By the definition of a credence good, it would be too expensive (or impossible) for each individual consumer to monitor the quality of the credence goods. An extensive-form game for a credence good with third-party monitoring is shown in figure 5 , where $f<0$ and $c>0$. With probability, $p$, the producer will be accurately monitored. ${ }^{5}$ The dotted lines denote information sets. The top two dotted lines indicate that the producer does not know whether he or she will be accurately monitored before making the choice of whether to make an organic claim and use organic methods. The bottom dotted line represents that the consumer does not know whether the producer will be accurately monitored or whether he or she used organic methods.

In the stage game, the probability of accurate monitoring makes this good a combination of an experience and a credence good. With probability $p$ the good will be an experience good, and with probability $(1-p)$ the good will be a credence good. Recall that in the stage game for both of

\footnotetext{
5 It could be that there is a probability, $p$, that the producer will be monitored, and that monitoring is $100 \%$ accurate. However, it may be that a higher percentage of producers are monitored, but that sometimes the monitor is tricked.
}

those types of goods, the producer's Nash Equilibrium strategy is to not use organic methods. While the consumer bought the credence good but did not buy the experience good in the stage game. Consequently, in the stage game, the Nash Equilibrium will depend on the level of monitoring, $p$. If $p \leq$ $c /(c-f)$, then the strategy profile (Not Organic, Buy) is the Nash Equilibrium in the stage game. Otherwise, the strategy profile (Not Organic, Don't Buy) is the stage game Nash Equilibrium. The intuition is that with a low level of monitoring, the monitored credence good is very similar to a pure credence good. While with a higher level of monitoring, the monitored credence good is similar to an experience good.

Now consider a game in which the stage game in figure 5 is infinitely repeated. Without loss of generality, I assume that both the consumer and producer have identical discount rates equal to $\delta$. Since the producer's actions are unobservable, the consumer's strategy is based on his/her observations. I assume that the consumer's strategy is common knowledge, and only the producer knows his/her own strategy. The proposed strategies are as follows:

Producer: Use organic methods in the first period. Then use organic methods if the consumer bought the product in each preceding period. Otherwise, do not make an organic claim.

Consumer: Buy in the first period. Then buy if the producer was not caught making a false organic all preceding periods. Otherwise, do not buy.

The present-value payoffs are listed in table 2 . The deviation payoffs are calculated based on one- 
Table 2. Credence Good with Monitoring Payoffs

\begin{tabular}{lcc}
\hline & $\begin{array}{c}\text { Equilibrium } \\
\text { Payoffs }\end{array}$ & $\begin{array}{c}\text { Deviation } \\
\text { Payoffs }\end{array}$ \\
\hline Producer & $\frac{a-b}{1-\delta}$ & $a-e+\frac{\delta(1-p)(a-b)}{1-\delta}$ \\
Consumer & $\frac{c}{1-\delta}$ & 0 \\
\hline
\end{tabular}

stage deviation. For the producer to use organic methods, we need

$$
\frac{a-b}{1-\delta}>a-e+\frac{\delta(1-p)(a-b)}{1-\delta} .
$$

This expression can be re-arranged as follows in order for a straightforward economic interpretation:

$$
p\left(\frac{\delta}{1-\delta}\right)(a-b)>b-e .
$$

In words, the expected loss of future profits must be greater than the one-time cost difference. This strategy profile describes a subgame perfect Nash equilibrium. Solving for $p$, the minimum level of accurate monitoring necessary to support this Nash Equilibrium is

$$
1 \geq p \geq \frac{b-e}{(a-b)}\left(\frac{1-\delta}{\delta}\right) \geq 0 .
$$

By definition, a probability must be between zero and one. The minimum necessary level of monitoring depends on the profitability of organic foods, the difference in costs of using organic versus conventional methods, and the discount rate. If the difference in costs of the two methods is large, then the probability of getting caught must also be high in order to support this equilibrium. The higher probability is needed to offset the large onetime reward in cost reduction. Similarly, if future profits from producing with organic methods are small, then the probability of getting caught must also be high in order to support this equilibrium. With small future profits, producers do not have much to lose by getting caught. Finally, if discount rates are low, then a higher probability is needed because producers are more willing to trade future profits for current profits.

\section{Policy Implications}

This analysis has shown that third-party monitoring of claims is necessary for efficient markets in organic foods. Following that conclusion, there are additional policy questions to consider. First, is setting national standards good policy, and should the government be responsible for monitoring? Although a final rule from the USDA is coming in the near future, there is presently no national definition of what constitutes an organic food product. Under the current system, some organic foods are certified under state and private certification programs. There are tradeoffs involved with setting national standards. On the positive side, standardization of the term "organic" will reduce the costs of monitoring and enforcement. It will also make labels easier for consumers to understand. Teisl and Roe (1998) make these arguments and point out that consumers are boundedly rational, which means that they face both time and cognitive constraints when interpreting labels. Consumers will also benefit if standardization and increased consumer confidence from monitoring cause markets to expand and to become more efficient, which results in lower prices.

The main drawback from national standards is the loss of flexibility and incentives for innovation. As Antle (1996) argues, inflexible design standards discourage innovation. Teisl and Roe (1998) expand on this inflexibility argument by pointing out that labeling can cause excess inertia or "lock-in" in the Farrel and Saloner (1985) sense. The point is that labeling standards do not adjust to changes in consumer preferences or technology. Standards can also limit choices. With a single standard, in general, there is no incentive for quality increases above the standard. There is also the incentive to use standards strategically, such as to create trade barriers. Given the inflexibility and inertia of standards, it is not surprising that the USDA's proposed rule for organic food standards created so much controversy.

From the model, effective monitoring is required for high-quality organic foods to be available. The model does not distinguish between government monitoring and private third-party monitoring. Although private programs may work effectively to correct market imperfections caused by asymmetric information (Caswell 1998), the government does have some advantages; it can standardize the term organic with certainty and prosecute violators under criminal law. Although it has not been the case with organic foods, private entities have 
achieved standardization in other areas. ${ }^{6}$ It is also possible for private third-party monitoring groups to effectively punish the fraudulent firm by creating bad publicity for them and/or coordinating civil law suits (Teisl, Roe, and Hicks 1998).

Although the preceding analysis has shown that monitoring is necessary for efficient markets in organic foods, the analysis does not tell us who should pay for monitoring. The information that comes from third-party monitoring is a public good. Each consumer would prefer for other parties to pay for the costs of monitoring. The usual resolution of a public-good issue is through collective action. The government could tax producers or consumers, so that the groups who benefit from monitoring pay for it. Similarly, producers could contribute to a private third-party monitoring group. If the groups who benefit from monitoring do not pay for its cost, then the implementation of monitoring should be able to pass a cost-benefit test. Labeling standards will produce benefits if consumers use label information and the truthfulness of labels is monitored. These benefits must be weighed against the additional costs that would be incurred by industry (Antle forthcoming).

Although it was not emphasized in the preceding analysis, the role of distributors and retailers (i.e., the marketing chain) has become important in organic food markets. While it may not be cost effective for an individual consumer, organic food markets often do bear the costs of searching for distributors who can verify organic claims. The consumer's information is then available through private programs and certification provided by the retailer. This role is considered in the game theoretic analysis presented earlier by applying it to the retail level with the consumer as the final customer and the retailer (seller) then would be considered the "producer."

\section{Conclusions}

Problems of asymmetric information can affect markets for quality-differentiated food products, such as organic foods. Food quality attributes are sometimes credence goods, which means that consumers cannot directly observe their quality even after consumption. As organic and other food products with unobservable quality attributes are increasingly marketed, these information issues will

\footnotetext{
${ }^{6}$ For example, the Financial Accounting Standards Board (FASB) is a private sector organization, which has achieved standardization of accounting rules and principles in the United States.
}

continue to gain prominence. The analysis in this paper shows that both a repeat-purchase relationship and third-party monitoring are required for high-quality credence goods to be available. If a producer is able to get away with making false quality claims, then he or she will enjoy a higher price with lower production costs. The minimum necessary level of monitoring depends on the price of organic foods, the difference in costs of using organic versus conventional methods, and the discount rate.

Although the focus of this paper is on organic foods, the analysis can be applied to any qualitydifferentiated product with asymmetric information. If consumers are willing to pay a premium for organic food products, a profit-maximizing producer has a strong incentive to falsely claim that his/her products are organic as long as the probability that he or she will not be discovered is high enough. From this analysis, the importance of certification and improved monitoring of organic claims is clear. Standardization of the organic claims and USDA certification may, therefore, improve market efficiency.

\section{References}

Akerlof, G. 1970. "The Market for 'Lemons': Qualitative Uncertainty and the Market Mechanism." Quarterly Journal of Economics 84:488-500.

Antle, J.M. forthcoming. "Economic Analysis of Food Safety." Handbook of Agricultural Economics. B.L. Gardner and G.C. Rausser, New York: Elsevier Science Publishing.

Antle, J.M. 1996. "Efficient Food Safety Regulation in the Food Manufacturing Sector." American Journal of Agricultural Economics 78:1242-47.

Barro, R.J. 1986. "Reputation in a Model of Monetary Policy with Incomplete Information." Journal of Monetary Policy 17:3-20.

Caswell, J.A. 1998. "How Labeling and Process Attributes Affects Markets for Food." Agricultural and Resource Economics Review 27:151-58.

Caswell, J.A. and E.M. Mojduszka. 1996. "Using Informational Labeling to Influence the Market for Quality in Food Products." American Journal of Agricultural Economics 78: 1248-53.

Caswell, J.A. and D.I. Padberg. 1992. "Towards a More Comprehensive Theory of Food Labels." American Journal of Agricultural Economics 74:460-468.

Darby, M. and E. Karni. 1973. "Free Competition and the Optimal Amount of Fraud." Journal of Law and Economics $16: 67-88$.

Emons, W. 1997. "Credence Goods and Fraudulent Experts." RAND Journal of Economics 28:107-119.

Farrell, J. 1993. "Meaning and Credibility in Cheap Talk Games." Games and Economics Behavior 48:514-31.

Farrel, J. and G. Saloner. 1985. "Standardization, Compatibil- 
ity, and Innovation." RAND Journal of Economics 16:7063.

Frazão, E. and J.E. Allshouse. 1996. "Nutritionally-Improved Foods in Supermarkets: 1989-93." The Economics of Reducing Health Risk from Food. J.A. Caswell, ed., pp. 14961. Storrs, CT: Food Marketing Policy Center.

Green, E.J. and R.H. Porter. 1984. "Noncooperative Collusion Under Imperfect Price Information.” Econometrica 52:87100.

Grossman, S.J. 1981. "The Informational Role of Warranties and Private Disclosure About Product Quality." Journal of Law and Economics 24:461-89.

Groves, M. 1998. "Firm Enters Plea in False Labeling Case." Los Angeles Times v117, n166 (Friday, May 15, 1998).

Hamilton, S.F., D.L. Sunding, and D. Zilberman. 1999. "Product Purity in Markets with Unobservable Quality." Unpublished paper.

Hooker, N.H. and J.A. Caswell, 1996. "Regulatory Targets and Regimes for Food Safety: A Comparison of North American and European Approaches." The Economics of Reducing Health Risk from Food. J.A. Caswell, ed., pp. 1-17. Storrs, CT: Food Marketing Policy Center.

Knoblauch, W.A., R. Brown, and M. Braster. 1990. "Organic Field Crop Production-Review of the Economic Literature." Cornell Agricultural Experiment Station AE Res. 90-10.

Kreps, D. and R. Wilson. 1982. "Reputation and Imperfect Information." Journal of Economic Theory 27:253-279.

Landay, J.S. "Organic Farmers to Washington: Regulate Us." Christian Science Monitor v89 n24 (Mon., Dec. 30, 1996): 3, col. 1 .
Milgrom, P. and J. Roberts. 1982. "Predation, Reputation, and Entry Deterrence." Journal of Economic Theory 27:280312.

Morgan, J., B. Barbour, and C. Greene. 1990. "Expanding the Organic Produce Niche: Issues and Obstacles." Vegetables and Specialties-Situation and Outlook Yearbook. Washington DC: U.S. Department of Agriculture, ERS TVS252.

Nelson, P. 1970. "Information and Consumer Behavior." Journal of Political Economy 78:311-329.

Patterson, G.A. 1992. "Sears's Brennan Accepts Blame for Auto Flap." Wall Street Journal, (June 3, 1992), pp. B1 and $\mathrm{dB} 14$.

Rabin, M. 1995. Ph.D.-Level Advanced Game Theory Lecture Notes. University of California, Berkeley.

Segerson, K. 1999. "Mandatory Versus Voluntary Approaches to Food Safety." Agribusiness 15:53-70.

Spence, M., 1973. "Job Market Signaling." Quarterly Journal of Economics 87:355-374.

Teisl, M.F. and B. Roe, 1998. "The Economics of Labeling: An Overview of Issues for Health and Environmental Disclosure." Agricultural and Resource Economics Review 27: 140-50.

Teisl, M.F., B. Roe, and R.L. Hicks. 1999. "Can Eco-labels Tune a Market? Evidence from Dolphin-Safe Labeling." Unpublished paper.

Tirole, J. 1992. The Theory of Industrial Organization. Cambridge, Massachusetts.

Vandeman, A.M. and B. Hayden. 1997. "New Law Paves Way for Expanding Organic Market." Food Review 20:28-32. 